\title{
Can Estimating Completeness of Death Registration be used as Evidence of Inaccuracy of Population Size Estimates from a Census? The Case of the 201 I South African Population Census
}

\author{
Eric O Udjo
}

\author{
Demographic Research Division \\ Bureau of Market Research \\ University of South Africa \\ Pretoria
}

bororue@yahoo.com; udjoe@unisa.ac.za

\begin{abstract}
Background: Knowledge about the size of the population is important for planning in any population. The census is the traditional source of information about population size. Accuracy of census figures can be in doubt even when a post-enumeration survey is used to adjust census figures. Results from the three post-apartheid censuses in South Africa are controversial. South Africa has a long history of death registration. Given the controversies surrounding South Africa's censuses, this study examines whether estimating completeness of death registration can be a tool for assessing the accuracy of the 201 I official census population estimate. Implication of inaccuracy of census figures on life expectancy at birth estimates is also examined.

Data Sources and Methods: The data for the study are South Africa's 200I and 20I I Censuses, 200 I and $20 \mathrm{II}$ Deaths registration. Estimation of completeness of death registration was based on the Growth Balance method.

Findings and Conclusion: The results indicate that using the official figures, the trend in completeness of death registration is illogical largely due to over-estimation of the population size in 201 I. This in turn produces over-estimation of life expectancy at birth in South Africa. It is important to get population figures as accurate as possible to avoid inefficient allocation of scarce resources.
\end{abstract}

Key words: Death registration completeness, life expectancy at birth, population size, post enumeration survey, South Africa

\section{Introduction}

Knowledge about the size of the population is indispensable for efficient planning and allocation of resources to various sectors in any population. In addition, the size of the population is used as denominator in demographic, epidemiological and other estimates, which in these contexts is referred to as "the population at risk" or "person years of exposure in experiencing an event". Information about the size of the population is conventionally obtained from censuses. But, because censuses are undertaken every ten or five years, census figures are usually updated by population projections with the last census as the base for the projections. Accuracy of census figures and hence the base of population projections can be in doubt even when a postenumeration survey (PES) has been undertaken and used to adjust the census figures.

South Africa has undertaken three post-apartheid censuses - in 1996, 200I and 20II. Although the 3133 census figures were adjusted using PES, the officially adjusted figures were controversial. Some of the contentions surrounding the post-apartheid censuses have been provided by Sadie (1999), Shell (1999), Phillips, et al. (1999), Udjo (2005, 20I4).

In addition to the censuses, South Africa has a long history of registration of deaths. Complete death registration data are useful for various purposes. From demographic and epidemiological standpoints, they constitute the numerator for mortality rates. Such estimates are important in gauging the wellbeing of the population from a health perspective. Complete death registration data are also important in examining outcomes of disease patterns in the population to enable the development of appropriate health intervention programmes. However, in many sub-Saharan Africa countries, their use is limited due to incomplete coverage of the population. Completeness of death registration in South Africa 
has been estimated by various researchers to have increased over time. For example, Groenewald et al. (2005) estimated completeness of death registration in the early 2000 s to be over $90 \%$.

A number of studies have utilised death distribution methods to estimate the completeness of death registration following the original method by Brass (197I) and its variants (see Preston \& Hill 1980, Preston et al. 1980, Bennett and Horiuchi 198I). The validation of the methods has been carried out among others, by Murray et al. (20I0) in the context of United States counties 1990- 2000 where due to law enforcements registration of deaths was assumed by the authors to be $100 \%$ complete. The methods have been applied in different contexts. See for example, Prasartkul and Vapattanawong (2006), Bhat (20l0), Khosravi et al (2007).

Estimates of the completeness of death registration often focus on the numerator of the estimates (number of registered deaths) and the results interpreted as "completeness relative to census count". See Hill (1987) - an implicit assumption that the errors are in the numerator of the estimates. However, there could be errors in the denominator of the estimates (the population at risk of experiencing deaths i.e. the estimated population size). If that were the case, this would produce inaccurate impression of the completeness of death registration. It appears therefore that estimating "completeness" of death registration could provide indications of the "accuracy" of official population size estimates from censuses.

\section{Objectives}

The overall objective of this study therefore is to assess whether estimating completeness of death registration can be a tool for assessing the accuracy of South Africa's 20II official census population estimate, comparing estimates of completeness of death registration in $200 \mathrm{I}$ and $20 \mathrm{II}$. Thus the question this study seeks to answer is: Does estimating completeness of death registration in South Africa provide evidence of inaccuracy in official population size estimates from the 201I South African population census? In an attempt to answer this question, the study examines: (I) the consistency in trends in completeness of death registration focusing on 200I and 20II; (2) completeness of death registration in $201 \mathrm{I}$ by province based on PES weighted 2011 Census population size as denominator; (3) the impact of assumed lower population size on estimated completeness of death registration in 20I I; and (4) the implication of overestimation of population size on life expectancy at birth.

\section{DATA}

The 200I and 20II Censuses

This study utilised the $200 \mathrm{I}$ and 20II South African Censuses as well as the $200 \mathrm{I}$ and $20 \mathrm{II}$ South African death registrations data, otherwise known as Causes of Death (COD) data. As already noted, three censuses have been undertaken in South Africa since the demise of apartheid in 1994, the 200I and 201I Censuses being the last two. The official estimate of the overall under-count in the $200 \mathrm{I}$ Census was $17.6 \%$ (Statistics South Africa, 2003). Thus, the size of the population in October (the month of the Census) 200I, adjusting for undercount, was $44,819,778$. The official estimate of the overall under-count in the 201 I Census was $14.6 \%$ and the size of the population in October 201 I, adjusting for undercount, was $5 \mathrm{I}, 770,560$ (Statistics South Africa, 20I2a). Controversies surround South Africa's postapartheid censuses. The controversies have been reported largely in the media and in a few unpublished monographs. Regarding the contention about the official estimates of the size of the population in the census years see, Sadie, 1999a, 1999b; Laubscher, 1999; Dorrington, 1999. Regarding the contention about the content of the Census data, see Shell, 1999, Phillips et al., 1999, Moultrie \& Dorrington, 2004; Dorrington et al., 2004; Udjo, 2004a, Udjo, 2004b, Udjo, 2004c, Udjo, 2005. The strengths and weaknesses of the 20II South African Census have been highlighted by Udjo (2014) although the focus was on the content rather than on the size of the population.

\section{The 200 I and 20 I I Causes of Death Data}

Vital registration, including registration of deaths, in South Africa dates back to 1910 (Khafani et al., 2005) and as indicated above, coverage was estimated to be over $90 \%$ in the 2000 s nationally. According to the deaths records, a total of 453,404 deaths excluding still births were registered in $200 \mathrm{I}$ while in $20 \mathrm{II}$, 505,803 deaths were registered excluding still births.

\section{Rationale for Choosing 200I and 20II as the bases for the Analysis}

$200 \mathrm{I}$ and $201 \mathrm{I}$ were the last two census years in South Africa. Thus, in addition to the census data, causes of death data are also available for these time periods. Assessing completeness of death registration requires the number of persons by age and sex as denominator for periods for which the estimates are desired. Although population projections of South Africa's population are available from different sources, the projections are also controversial, due, in part, to the base populations used as well as the assumptions in the projections. Since the main focus in this study is on assessing the accuracy of the official 
estimate of the size of South Africa's population in 20II, the choice of $200 \mathrm{I}$ and $20 \mathrm{II}$ periods was considered more appropriate given the above context. Comparing $200 \mathrm{I}$ and $20 \mathrm{II}$ results in the analysis would provide some indication of trend and assessment of the plausibility of the trend. Aside adjusting the census figures to mid-year of the census years (as is conventionally) done, no other adjustments were made to any of the data used in this study before the application of the methods described below.

\section{METHODS}

\section{Underlying Premise in the Analysis}

Death registration is compulsory by law in South Africa and in theory, one cannot bury a deceased without a death certificate. Unlike some African countries, in South Africa, the deceased is usually buried within a very short time after death - between I-2 weeks. Therefore, even if death registration were delayed, it should not be by a factor of one year. Thus, lateness of death registration should not be a valid argument for substantial incomplete registration of deaths in a particular year. However, in personal communication with Statistics South Africa (the official statistical agency), they pointed out that not all deaths are registered, particularly in the rural areas and among young children. They further informed that although by law a burial order is required before burial, it is not enforced in the rural areas. This notwithstanding, if population size estimates from censuses are accurate, trends in completeness of death registration should increase with time, since the system of vital registration should become more efficient over time. The system of vital registration in South Africa dates back to 1910 (Khafani et al., 2005). In view of this, if one were to apply an appropriate model such as the Growth Balance method to estimate completeness of death registration and a declining trend were obtained, this would be indicative of an over-estimate in the official estimates of population size since population size is the denominator in such application.

\section{The Growth Balance Method}

Brass Growth Balance method (197I) can be used to assess the completeness of death registration with a cautionary interpretation of the results given the above premise. The model is based on the linear relationship of deaths and age distributions that may be expressed as:

$$
N(x) / N(x+)=r+k(D(x+) / N(x+))
$$

Where $N(x)$ is the number of persons at exact age $x$, $N(x+)$ is the total number of persons above age $x$,
$D(x+)$ is the total number of deaths occurring to persons aged $x$ and over, and $r$ is the growth rate. This implies that there should be a straight line relationship of intercept $r$, slope $k$, a coefficient of the estimated ratio of true to reported deaths (a factor representing the completeness of reporting of deaths). Further extension of the method has been provided by Hill (1987). The method assumes that the population is (I) closed to migration, (2) demographically stable, (3) completeness of death recording is constant at all ages, and (4) completeness of census coverage was constant at all ages (Hill, 1987). Concerning the assumption of closed migration, if there were substantial net migration in the population under study, this would be discernible in the pattern produced in the application of the method to the data: upward arching of the points denoting net excess immigration or downward arching of the points denoting net excess emigration.

Regarding the assumption of stability, it has been observed on the basis of simulations that the bias introduced in the estimation of the coefficient of the completeness of reporting of deaths is relatively small (see UN, 1983) cited in Udjo (2006). A careful examination and selection of the points in fitting the model can overcome the violation of assumptions 3 and 4 above (see Udjo, 2006).

In the application of the method, $N(x) / N(x+)$, which is synonymous to a partial birth rate, is plotted against $D(x+) / N(x+)$, which is synonymous with a partial death rate (see Brass, 197I). If no errors in the data, the plot should lie on a straight line if the assumptions underlying the model are not seriously violated. Next, a straight line is fitted to the "best" points. The slope and intercept of the straight line are then computed. The completeness of death registration, $c$ is then derived from the slope as $I / k$.

\section{Life Table Estimate of life Expectancy at Birth}

In computing life expectancy at birth from the data, the observed age-specific death rates were adjusted using the estimated coefficient of completeness of death registration for the specific periods. Next, life tables were constructed from the adjusted agespecific death rates to derive life expectancies at birth. Detailed methodology of life table construction is given, among others, by Preston et al.(200I).

\section{RESULTS}

Consistency and Trend in Completeness of Death Registration, 200I and 20II

Figures I-4 show the results of fitting the Growth Balance method to the 200I and 20II COD among registered number of deceased males and females. Although roughly linear, the scatter plots do not fall on a straight line. The straight line was fitted to the http://aps.journals.ac.za 
points corresponding to registered number of deceased persons aged 20 years and over except for females in the 201I COD, where it was fitted to registered number of deceased aged 10 years and over because the linearity of the points were better than those for the 200I COD. That the points do not fall on a straight line is an indication of errors in the data. The choice of the points to use in the fitting often presents a challenge and would depend on the quality of the data in the selection of the "best" fitting points. The points corresponding to older persons (I5 years and over) often produce a better fitting than the inclusion of points corresponding to persons younger than 15 years. In the present application, it can be seen that there is a downward curving in the first three points (Figures I-5), which is an indication that the quality of the reports corresponding to deceased persons aged 0-14 years were of poorer quality (a combination of age errors and larger omission) than deceased persons aged 15 years and over.

The parameter estimates (shown at the bottom of the graphs) suggest that in $200 \mathrm{I}$, the completeness of registration of adult deaths among males was about $97 \%$ ( c $=0.974)$ and apparently decreased to about $81 \%(c=0.809)$ in 2011. Among females, it apparently decreased from $86 \%(c=0.860)$ in 200 I to about $81 \%(c=0.809)$ in $201 \mathrm{I}$. Thus, the trend in the completeness of death registration, comparing $200 \mathrm{I}$ and $20 \mathrm{II}$, is inconsistent with the underlying premise explained above. A plausible explanation for the illogical trend is over-estimation of the population size (the denominator in fitting the Growth Balance method) as given by official estimates from the 20I I Census. It is probable that official estimates from the
200I Census also over-estimated the population size in 200I. However, in view that the estimated completeness of registration of adults deaths was over $90 \%$ using the 2001 Census figures as denominator in the estimates, suggests that overestimation of population size in the official census figures in 200I was probably far less substantial than in the 2011 figures. Further indication of overestimation of population size by official 20II Census figures are provided in the following sections.

\section{Completeness of Death Registration in 20 I I Using PES Weighted 20II Census Figures as} Denominator

In the October 201I South African Census, $44,220,397$ persons were enumerated. This figure was adjusted upwards officially to $5 I, 770,560$ using the post-enumerated survey (PES) as weights (Statistics South Africa, 20I2b). Adjusting to mid-year $20 \mathrm{II}$, this translates to about $5 \mathrm{I}, 506,749$ persons. Table I shows the results of fitting the Growth Balance method to the 20II COD by province and sex. The denominator in the estimates is the PES adjusted population, which were then adjusted to the middle of 201 I since the census was undertaken in October. In most cases, the straight line was fitted using the age range $20-65$ due to the quality of the provincial data. The estimated national completeness should therefore not be interpreted as the average of the estimated provincial completeness. It is well known that quality of data is often better at the national level than at lower levels.

Table 1: Estimated Percent Completeness of Death Registration by Province and Sex, 2011

\begin{tabular}{|l|c|c|}
\hline \multicolumn{1}{|c|}{ Province } & \multicolumn{2}{c|}{ Percent Completeness } \\
\hline Eastern Cape & Male & Female \\
\hline Free State & 68.5 & 65.6 \\
\hline Gauteng & 82.3 & 82.1 \\
\hline KwaZulu-Natal & 61.9 & 67.2 \\
\hline Limpopo & 68.6 & 77.2 \\
\hline Mpumalanga & 78.2 & 83.4 \\
\hline North West & 69.0 & 66.5 \\
\hline Northern Cape & 68.8 & 68.5 \\
\hline Western Cape & 81.2 & 78.9 \\
\hline Total & 70.5 & 70.1 \\
\hline
\end{tabular}

As seen from Table I, the estimated completeness of adult death registration ranges between $61.9 \%$ (in
Gauteng) to $82.3 \%$ (in the Free State) among deceased males and between $65.6 \%$ (in the Eastern 
Cape) to $83.4 \%$ (in Limpopo) among deceased females.

Completeness of registration of deaths of males in Gauteng was apparently the lowest of all the provinces and for females, apparently the second lowest level of completeness of all the provinces. This is odd considering that: (a) Gauteng is the most economically developed province and economic hub of the country with highly developed infrastructure and social services; (b) It is the most urbanised province in the country ( $97 \%$ urban according to computations derived from the 20II Census figures by this author). In contrast with Limpopo, for example, only about $18 \%$ of the population lived in urban areas yet completeness of registration of adults deaths was estimated as $81 \%$ in $201 \mathrm{I}$ (Table I). Given this context, it is not logical that Gauteng province would have the lowest level of completeness of death registration. Contrary to

Impact of Assumed lower Population Size on Estimated Completeness of Death Registration in 20II

Over-estimation of population size has an impact on the level of estimated completeness of death registration. This is illustrated as follows. If one assumes that the official estimates from the 20II Census over-estimated the population of South African males by $10 \%$ and, for simplicity, further assume that the over-estimation was constant at all ages (not correct in reality), the resulting scatter plot from fitting the Growth Balance method to the data is reflected in Figure 5. The parameter estimatesfitting a straight line to the points corresponding to the registered deceased males aged 20 years and over, suggest completeness of registration of about $90 \%(c=0.899)$. It can be seen from this simplistic illustration that the probable reason for the apparent decline in completeness of death registration in South Africa comparing 200I and $20 \mathrm{Il}$, is over-estimation of the size of the population by official estimates.

\section{Implication of Over-Estimation of Population Size on Life Expectancy at Birth}

In the usual application of the Growth Balance method to assess completeness of death registration or reported number of deaths by households, in a specified period before a census or survey, the coefficient of completeness is used to adjust observed age-specific death rates. A life table is then expectation if one were to argue the issue of migration, in the application of the method, there was a perceptible curving downwards of the points from a straight line for older persons for Gauteng province (graph not shown) which theoretically, may be interpreted as net excess emigration from Gauteng. This is odd considering that Gauteng is a major receiving province of internal and international migrants. A more plausible explanation lies in the denominator of the estimates - the population of Gauteng in 20II was probably over estimated to a greater extent than that of any other province by the official census figures. Previous studies in Latin America (Jaspers-Faijer \& Orellana 1996, PiscoyaDiaz \& Queiroz 2010) show that completeness of death registration was closely associated with the level of development. This was inconsistent in the South African case as seen in the above provincial results.

computed from the adjusted age-specific death rates to obtain life expectancies. It therefore follows from this, that if the size of the population is over-stated: (I) the completeness of death registration would be underestimated. (2) Life expectancy at birth would be over-estimated since the adjustment factor for the age-specific death rates from (I) above is underestimated. This is because the population size in each age group is the denominator in computing the agespecific death rates. Let us now examine the implication of the above on life expectancy at birth with regard to South Africa in $20 \mathrm{I} \mathrm{l}$.

Two sets of life expectancy at birth by province and sex are shown in Table 2. The first set is based on computed life tables after adjusting the age specific death rates using the adjustment factor derived from fitting the Growth Balance method to the 20II COD and using the official figures of population size adjusted by the PES as denominator. The second set is based on computed life tables after adjusting the age-specific death rates from deaths reported by households in the 201 I Census using the adjustment factor derived from fitting the Growth Balance method to the data but without using the PES weights. Thus, the numerator in the observed age-specific death rate in the second set of life expectancy at birth consisted of the number of deaths in five-year age groups reported by households in the 12-month period preceding the $20 \mathrm{II}$ Census, and the denominator consisted of the enumerated population in five-year age groups. 
Table 2: Implication of Over-Estimation of Population Size on Life Expectancy at Birth

\begin{tabular}{|l|c|c|c|c|}
\hline \multirow{2}{*}{} & \multicolumn{3}{|c|}{ Estimated Life Expectancy at Birth } \\
\cline { 2 - 5 } & \multicolumn{2}{|c|}{$\mathbf{2 0 1 1}$} & \multicolumn{2}{c|}{ 2011 } \\
\hline Province & \multicolumn{2}{|c|}{ Death Registration } & \multicolumn{2}{c|}{ Census Household Deaths } \\
\hline Eastern Cape & Male & Female & Male & Female \\
\hline Free State & 55.7 & 60.9 & 49.0 & 51.8 \\
\hline Gauteng & 52.6 & 55.8 & 50.5 & 56.7 \\
\hline KwaZulu-Natal & 63.3 & 66.2 & 57.1 & 59.6 \\
\hline Limpopo & 55.9 & 62.1 & 47.5 & 53.1 \\
\hline Mpumalanga & 59.4 & 66.8 & 53.5 & 60.8 \\
\hline North West & 57.3 & 59.9 & 54.6 & 57.7 \\
\hline Northern Cape & 58.2 & 62.5 & 56.1 & 61.8 \\
\hline Western Cape & 55.6 & 59.4 & 56.8 & 62.7 \\
\hline RSA & 65.1 & 71.6 & 63.5 & 68.5 \\
\hline
\end{tabular}

As seen from Table 2, except in the Northern Cape, the life expectancy at birth derived from the 20II COD data (PES weighted population size) are consistently higher that those derived from the number of deaths reported by households in the 2011 Census (without PES weights). For example, at national level, the 20II COD and using official population size estimate from the 201 I Census gives the impression that life expectancy at birth among females in South Africa was 64 years in 201I while analysis of the distribution of deaths as reported by households in the 20II Census, without using PES weights, suggests life expectancy at birth of 56.9 years among females in 201 I. The same method was used in the estimates in the two sets of life expectancies shown in Table 2 except that as indicated above, different denominators in the estimates. In view of these results, mortality estimates using the $201 \mathrm{I}$ official Census figures as denominator, or mid-year population projections that used the 20I I census figures as a base, are arguably biased.

\section{DISCUSSION AND CONCLUSION}

Given that by law in South Africa, one should not bury a deceased without a death certificate, and although not all deaths are registered particularly in the rural areas and among young children, trends in the level of completeness of death registration in South Africa should increase and probably be close to $100 \%$. However, the comparison of the estimated level of completeness of registration of deceased adults in $200 \mathrm{I}$ with that in $20 \mathrm{II}$ indicates that the level was "lower" in 2011 (8I\%) than in 200I (92\%). This is illogical. The provincial pattern of completeness of death registration is also illogical: the most economically developed and most urban province (Gauteng) had an estimated completeness of registration of adult deaths of about $65 \%$ in 2011 while in the same year the least economically developed and most rural province (Limpopo) had an estimated completeness of registration of adult deaths of about $81 \%$.

The results in this study suggest that these inconsistencies are most probably due to overestimation by official census figures of the population size of South Africa's population in 201 I nationally, and in particular in Gauteng to a greater extent than in other provinces in South Africa. The October 201 I South African Census enumerated 44,220,397 persons but using the PES, the size of the population was adjusted officially to $51,770,560$ which translates to about 5I.5I million in mid-20II. The Bureau of Market Research estimated the population of South Africa in mid-20II as 50.33 million (see Udjo \& Kembo, 20I I). Statistics South Africa's own estimate of the population of South Africa in mid-20II was 50.59 million (see Statistics South Africa, 20l I). It would appear from the results in this study that the PES adjustments (of I4.6\%) on the 20 I I South Africa Census may have been too high. In view of the above results, it is unlikely that South Africa's population in October $20 \mathrm{II}$ was $5 \mathrm{I} .8$ million. It was probably less than $5 \mathrm{I}$ million.

According to Statistics South Africa, "overall completeness of adult (I5 years and older) death registration for the inter-censal period 1996-200I was estimated at $89 \%$, for the period 200I-2007 the level of completeness was $93 \%$ and for the period 2007-20 I period it was estimated at $94 \%$. This indicates that there has been an increase, though modest, in the registration of adult deaths" (Statistics 
South Africa, 201 I:6). Unfortunately, the report does not provide the graphs resulting from the analysis to show how these figures were arrived. The present study argues firstly, if the Growth Balance method were appropriately applied to the data, it is not possible to obtain a $94 \%$ completeness in adult registration from the 201I COD using the 201I Census figures as denominator. Secondly, using official figures and appropriate application of the Growth Balance method, it is not possible to infer from the results that there was an increase in completeness of adult death registration comparing 200 I completeness of death registration with that in 201 I. Although the expectation is that of an increase in trend in completeness of death registration, using official census figures as denominator in the estimates, does not confirm this expectation but rather the opposite.

Using official estimates of population size from the 20II Census presents other problems since they are used as the base for official mid-year projections. One of the problems is estimates of life expectancy at birth for recent years. Since the life tables derived from causes of death in 2012 onwards utilise the midyear estimates as denominator in computing the age specific death rates, life tables derived from these rates appear to over-estimate life expectancy at birth for the country. Official life expectancy at birth given for South Africa should therefore be seen in this context if in the estimation, mid-year estimates were utilised in computing the age-specific death rates. In view of the above, mortality estimates on South Africa using either the 20I I Census figures or official mid-year estimates as denominator should be treated with caution. Although the focus in this study has been on the denominator in estimating the completeness of death registration, this does not mean that the numerator of the estimates is error free. Some limitations in this study need to be noted. The study recognises that registration of deaths in South Africa is not $100 \%$. Additionally, because of the quality of the data, it was not possible to use the same age range in fitting the straight line in the national and provincial data points in the application of the Growth Balance method. Despite these limitations, the study contends that the trend in completeness of death registration should increase and close to $100 \%$. This was not the case using official census figures as denominator in the estimates. Despite omissions that may be present in the numerator of the estimates, this study demonstrate that estimating completeness of death registration may be used to assess the accuracy of population size estimate from a census in contexts where laws governing burial of deceased and practices point to completeness of death registration 3139 that is close to $100 \%$. One of the implications of the results in this study has to do with resource allocation. Population numbers are a key input in allocation of resources to different sectors nationally and provincially. If population size is overestimated by official census figures, this could result in inefficient allocation of scarce resources to provinces.

Furthermore, indicators are often computed and by comparing these overtime, are used to track progress in the wellbeing of the population. The denominators for computing such indicators (demographic, epidemiologic and socio-economic) are usually obtained from population size estimates or mid-year estimates using census figures as a base. If the census based figures are over stated as demonstrated above, the computed indicators would be biased and give a false impression of progress in the wellbeing of the population. It is therefore imperative to get the population figures as accurate as possible to avoid inefficient allocation of scarce resources and false impression of developmental progress.

\section{ACKNOWLEDGEMENT}

The author wishes to thank Statistics South Africa for providing access to their data as well as African Population Studies' anonymous reviewers for their helpful comments and suggestions on the previous version of this article. The views expressed in this study are, however, those of the author.

\section{REFERENCES}

Bennett, N.G., Horiuchi, S. 198I. Estimating the completeness of death registration in a closed population. Population Index, 47, (2): 207-22I.

Bhat, P.N.M. 2002. Completeness of India's sample registration system: an assessment using the general growth balance method. Population Studies, 56, (2): II 9-I34.

Brass, W 197I. Methods for estimating fertility and mortality from limited and defective data. Chapel Hill: The University of North Carolina.

Dorrington, R 1999a. Did they jump or were they pushed? An investigation into the apparent undercount of whites in the 1996 census, Paper presented at the Workshop on Phase 2 of Census 1996 Review, Wanderers Club, Johannesburg, 3-4 December.

Dorrington, R 1999b. To count or to model that is not the question: some possible deficiencies with the 1996 census results, Paper presented at the Arminel Roundtable Workshop on the 1996 South Africa Census, Hogsback, Eastern Cape, 9-II April.

Dorrington, R and Moultrie, T 2004. Estimation of mortality using the South Africa census data. http://aps.journals.ac.za 
Statistics South Africa Workshop on the 200I population census, Statistics South Africa, Pretoria.

Groenewald, P., Nanna, N., Bournde, D., Laubscher, R. and Bradshaw, D 2005. "Identifying deaths from AIDS in South Africa", AID 19, (2 ): 193-20I.

Hill, K 1987. "Estimating census and death registration completeness", Asian and Pacific Population Forum, I, (3): 8-13.

Jaspers-Faijer, D., Orellana H. 1996. Evaluation of vital statistics for the study of causes of death. In. Timaeus, I., Chackiel, J., \& Ruzick, L.T. Adult mortality in Latin America. Oxford: Oxford University Press, pp. 45-68.

Khalfani, A.K., Zuberi, T., Bah, S. and Lehhola, P.J. 2005. Population Statistics, In, Zuberi, T., Sibanda, $A$ and Udjo E (eds), The demography of South Africa, New York: M. E. Sharp, pp 3-39.

Khosravi, A., Taylor, R., Naghavi, M., Lopez, A.D. 2007. Mortality in the Islamic Republic of Iran, 1964-2004. Bulletin of the World Health Organisation, 85, (8): 607-6I4.

Laubshcher, N.F 1999. Van rou data tot populasiegrootte. In, Investigation by demographers into the 1996 census results for the Western Cape, Western Cape Cabinet. Cape Town.

Moultrie, T. and Dorrington, R 2004. Estimation of fertility from the 200I South Africa census data, Statistics South Africa Workshop on the 200I population census.

Murray, C.J.L., Rajaratnam, J.K., Marcus, J., Laakso, T., Lopez, A.D. 2010. What can we conclude from death registration? Improved methods for evaluating completeness. Plos Medicine, http://dx.doi.org//0.1371/journal.pmed.I000262. Accessed 25 January 2017.

Piscoya-Diaz, M., Queiroz, B.L. 2010. What do we know about adult mortality and data quality in Peru? Mortality coverage levels and trends from recent decades. Papeles de POBLACION, 63: 2|9-24|.

Prasartkul, P., Vapattanawong, P. 2006. The completeness of death registration in Thailand: evidence from demographic surveillance system of the Kanchanaburi project. World Health and Population, March 2006.

Preston, S., Hill, K. 1980. Estimating the completeness of death registration. Population Studies, 34, (2): 349-366.

Preston, S., Coale, A.J., Trussell, J., Weinstein, M. 1980. Estimating the completeness of reporting of adult deaths in populations that are approximately stable. Population Index, 46, (2): I79-202.

Sadie, J.L 1999a. The missing millions, Paper presented to NEDLAC (National Economic
Development and Labour Council) meeting, Johannesburg.

Sadie, J.L 1999b. An evaluation of the 1996 census results. In, Investigation by demographers into the 1996 census results for the Western Cape, Western Cape Cabinet, Cape Town.

Statistics South Africa 2003. Census 200I: How the count was done, Statistics South Africa, Pretoria. Available

on: www.statssa.gov./census/census 200I/theCount/ Count.pdf

Statistics South Africa 201I. Mid-year population estimates 20 I I, Statistics South Africa, Pretoria.

Statistics South Africa 2012a. Census 201I: How the count was done, Statistics South Africa, Pretoria. Available

on: www.statssa.gov./census/census 201 I/census_pr oducts/census 201I How the count was done. pdf

Statistics South Africa 20I2b. Census 20ll: Methodology and highlights of key results, Pretoria: Statistics South Africa.

Statistics South Africa 2014. Mortality and causes of death in South Africa, 20I I: Findings from death notification. Pretoria: Statistics South Africa.

Phillips, H. E., Anderson, B. A., Anderson, B. A and Tsebe, $P$ 1999. Sex ratios in South African census data 1970-1996. Paper presented at the Workshop on Phase 2 of Census 1996 Review on Behalf of the Statistical Council, Johannesburg, 3-4 December.

Preston, S.H., Heuveline, P and Guilot, M $200 \mathrm{I}$. Demography: Measuring and modeling population processes. Oxford: Blackwall publishers, pp.3870.

Udjo, E.O 2004a. Comment on R. Dorrington's To count or to model that is not the question, Paper presented at the Arminel Roundtable Workshop on the 1996 South Africa Census, Hogsback, Eastern Cape, 9-II April.

Udjo, E.O 2004b. Comment on Moultrie and Dorrington: Estimation of fertility from the 200 I South Africa census data, Statistics South Africa Workshop on the 200I population census, Pretoria: Statistics South Africa.

Udjo, E.O 2004c. Comment on Dorrington et al.: Estimation of mortality using the South Africa census 200I data, Statistics South Africa Workshop on the 200I population census. Pretoria: Statistics South Africa.

Udjo, E. O 2005. "An evaluation of age-sex distribution of South Africa's population within the context of HIV/AIDS", Development Southern Africa, 22, (3): 319-345. 
Udjo, E.O 2006. "Estimation of mortality from vital registration in South Africa". Current HIV Research, 4 : 469-474.

Udjo, E.O and Kembo J 20II. Population estimates for South Africa by district municipality and province, 2010, Bureau of Market Research,
Research Report No 402, University of South Africa, Pretoria.

Udjo, E.O 2014. "Estimating demographic parameters from the 20II South Africa population census", African Population Studies, 28, (I) : 564578.

Figure I: Plot of partial birth rate, $N(x) / N(x+)$, against partial death rates, $D(x+) / N(x+), 200$ I COD, South Africa: Males

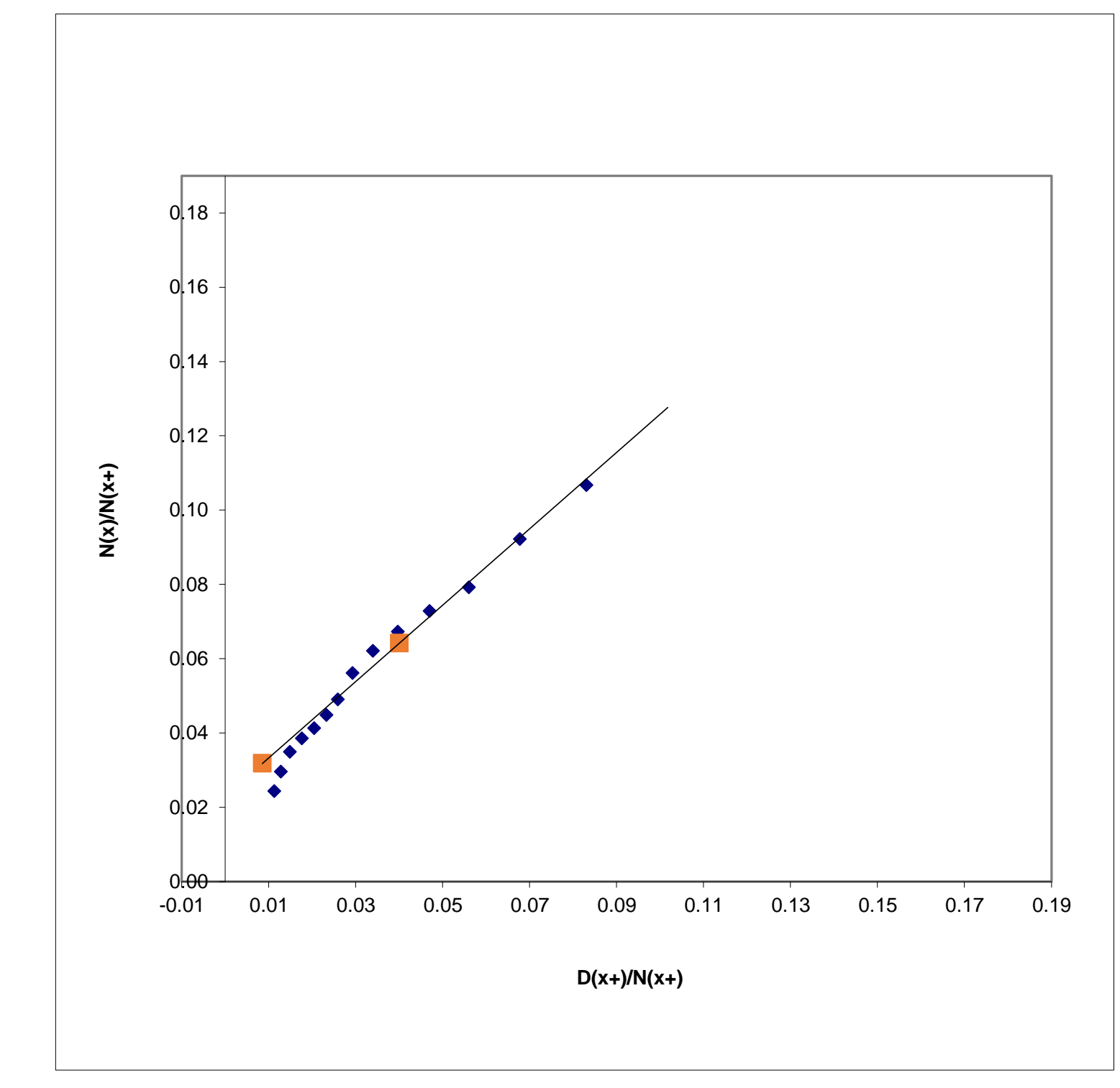

$\mathrm{r}=0.023 \mathrm{I}, \mathrm{k}=1.0272, \mathrm{c}=0.974$ 
Figure 2: Plot of partial birth rate, $N(x) / N(x+)$, against partial death rates, $D(x+) / N(x+), 20$ I I COD, South Africa: Males

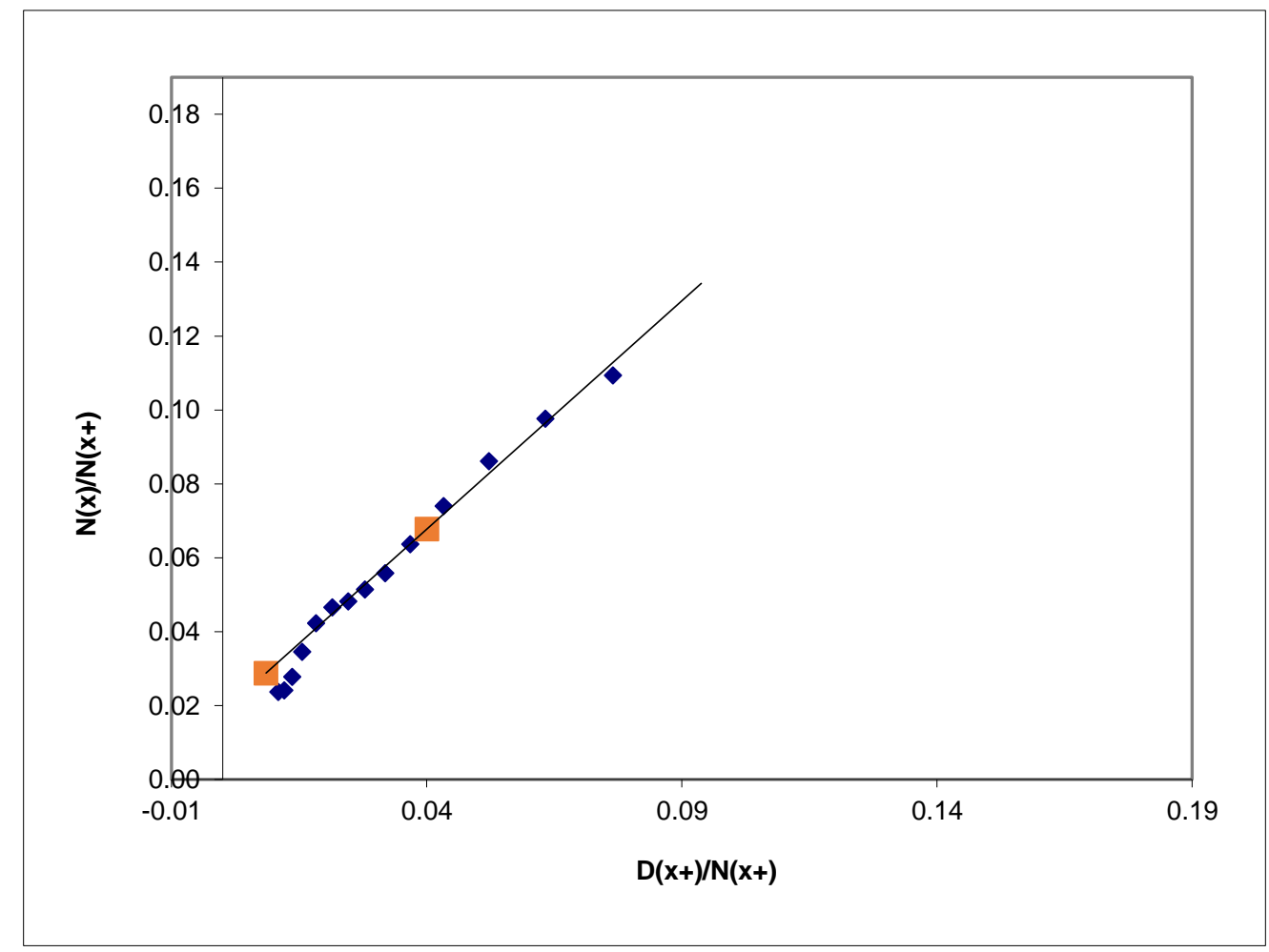

$$
r=0.0183, k=1.2359, c=0.809
$$

Figure 3: Plot of partial birth rate, $N(x) / N(x+)$, against partial death rates, $D(x+) / N(x+), 200$ I COD, South Africa: Females

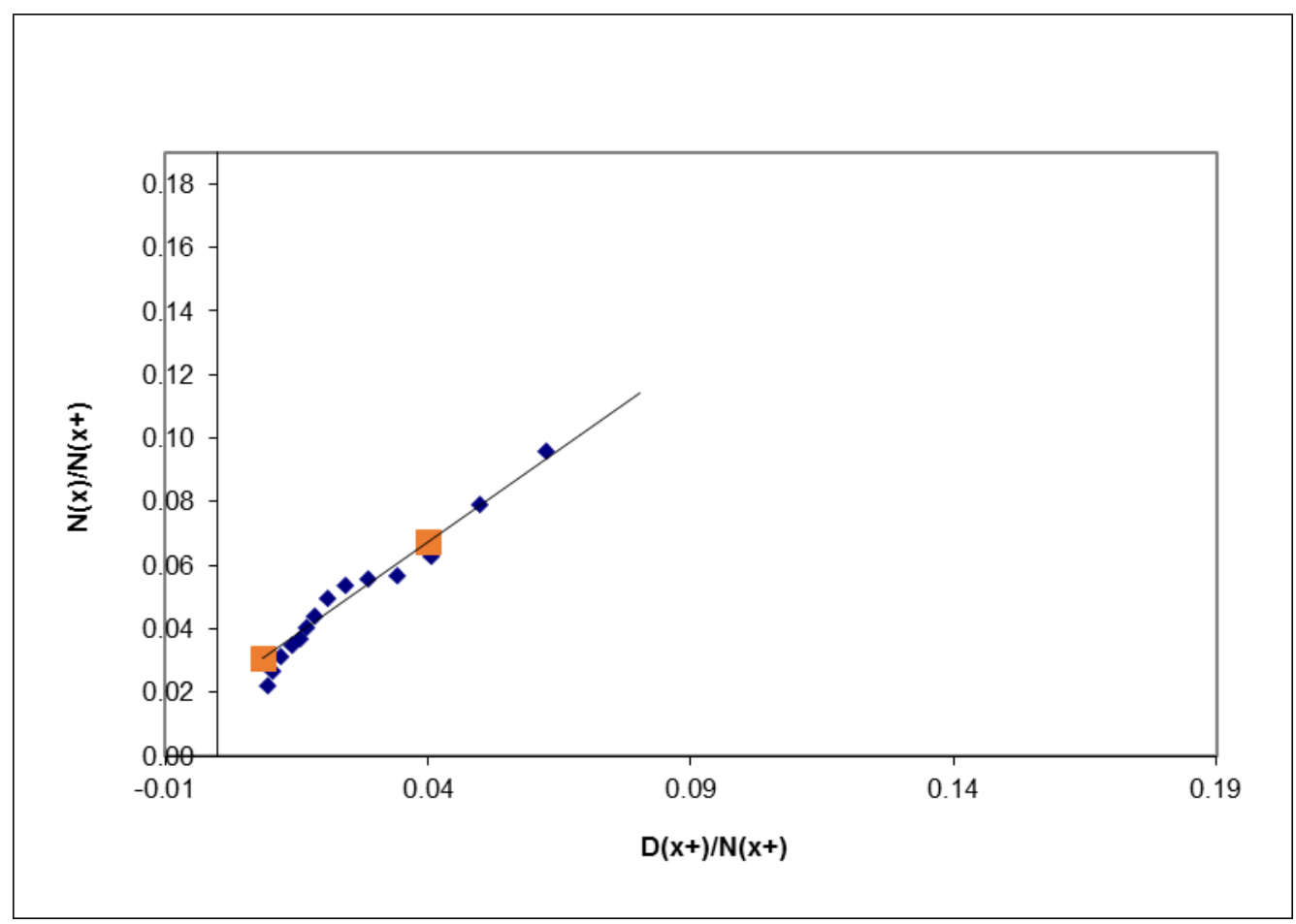

$$
a=0183, b=1.1123, c=0.899
$$


Figure 4: Plot of partial birth rate, $N(x) / N(x+)$, against partial death rates, $D(x+) / N(x+), 20$ I I COD, South Africa: Females

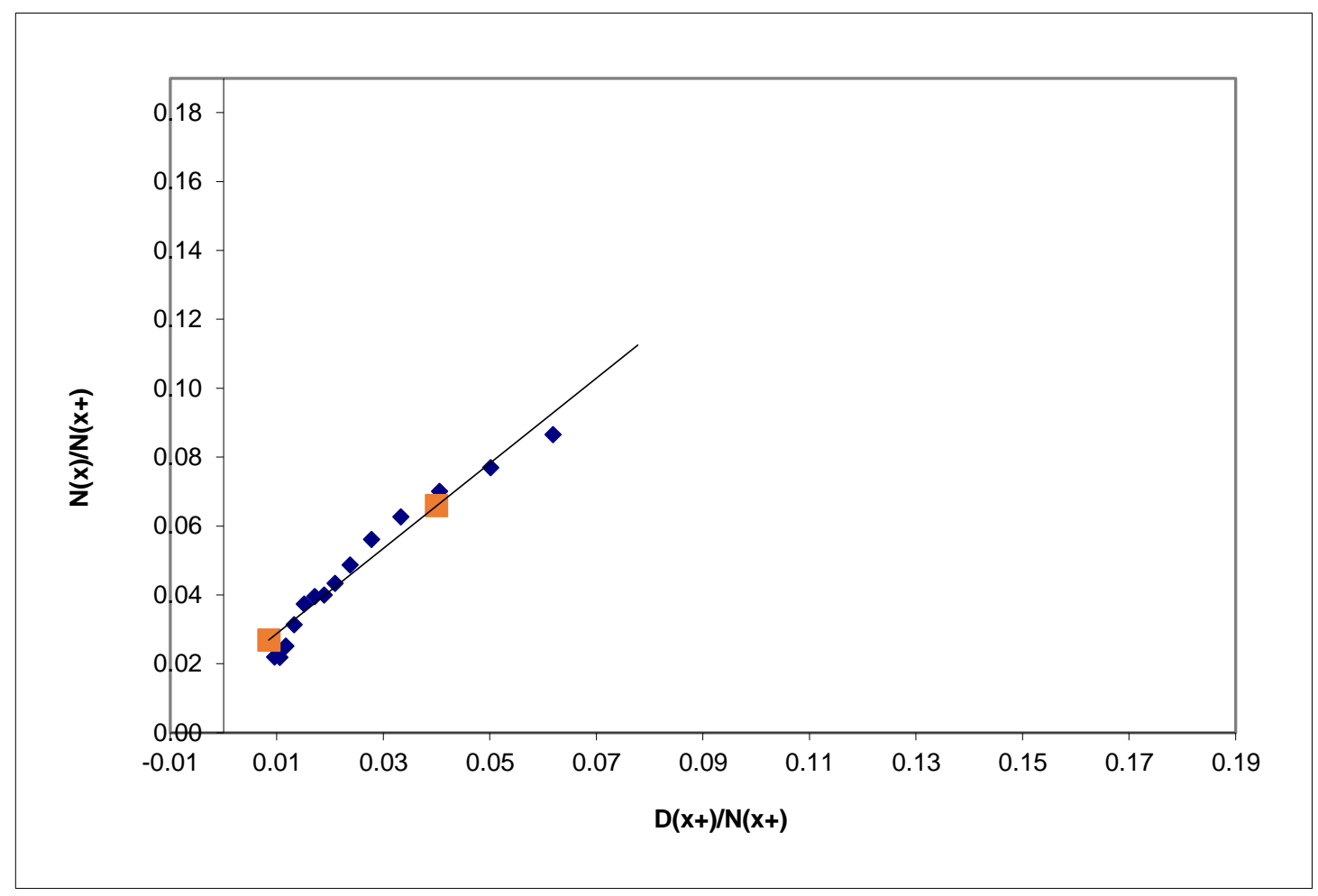

$r=0.0164, k=1.2366, c=0.809$ 